\title{
Ocular surface squamous neoplasia in HIV- positive and HIV-negative patients and response to 5-fluorouracil in Angola
}

This article was published in the following Dove Press journal:

Clinical Ophthalmology

I December 20|4

Number of times this article has been viewed

Robert J Nutt ${ }^{\prime}$

John L Clements ${ }^{2}$

William H Dean ${ }^{3}$

'Faculty of Medicine and Dentistry, University of Bristol, Bristol, UK;

${ }^{2}$ Boa Vista Eye Clinic, Benguela, Angola; ${ }^{3}$ Bristol Eye Hospital,

Bristol, UK
Correspondence: Robert J Nutt 212 Manor Road, Witney, OX 28 3ST, UK

Tel +4478 3749674 I

Email rn6I78@my.bristol.ac.uk
Background: Ocular surface squamous neoplasia (OSSN) is becoming increasingly prevalent and aggressive in Sub-Saharan Africa. It is a phenomenon linked with human immunodeficiency virus (HIV) infection, although association rates in Angola are currently unknown. A topical treatment that is effective in HIV-positive and HIV-negative individuals may be preferable to surgery in some contexts. We aimed to estimate the proportion of OSSN associated with HIV in Angola and to report on the success of topical 5-fluorouracil as a primary treatment in HIVpositive and HIV-negative patients.

Methods: Photographs of OSSNs taken at presentation and following treatment with 5-fluorouracil in patients presenting to Boa Vista Eye Clinic, Angola, between October 2011 and July 2013 were grouped into HIV-positive and HIV-negative groups and analyzed to compare presenting features and treatment response. Eighty-one OSSNs were analyzed for clinical features and 24 met the inclusion criteria for analysis of treatment response.

Results: Eighty-two patients presented with OSSN between October 2011 and July 2013. Twenty-one (26\%) were HIV-positive and typically had OSSNs that exhibited more pathological features than those in HIV-negative patients. Twenty-four (29\%) patients met the inclusion criteria for analysis of treatment response; of these, 26 (91\%) OSSNs in both groups displayed at least partial resolution after one treatment course. In the HIV-positive group, five of eight patients displayed complete resolution, two showed partial resolution, and one failed. In the HIV-negative group, five of 16 showed complete resolution, ten of 16 had partial resolution, and one failed.

Conclusion: Individuals presenting with OSSN in Angola are more likely to have HIV infection compared with the general population. Regardless of HIV status, 5-fluorouracil drops can be an effective strategy for management of OSSN without incurring the costs and risks of surgery in the developing world setting.

Keywords: ocular surface squamous neoplasia, 5-fluorouracil, Angola, Sub-Saharan Africa

\section{Introduction}

Ocular surface squamous neoplasia (OSSN) refers to a spectrum of conjunctival and corneal epithelial disease including mild to severe dysplasia, intraepithelial carcinoma, and invasive carcinoma. ${ }^{1}$ OSSNs have become more prevalent and aggressive over recent decades in Sub-Saharan Africa, with higher rates of young people being affected. ${ }^{2}$ These changes are largely attributed to human immunodeficiency virus (HIV) infection. ${ }^{3-6}$ A study in Uganda and Malawi have estimated HIV to be associated with OSSN in $71 \%$ and $84 \%$ cases, respectively. ${ }^{7}$ Association rates in Angola are currently unknown, but may differ markedly from other Sub-Saharan nations due to a lower HIV prevalence. 
Concordant with these changes, there have been shifts in the management of OSSN. Wide local excision with supplementary cryotherapy has traditionally been the mainstay of treatment, ${ }^{8-10}$ but in resource-poor settings where histopathology is unavailable and high HIV rates pose potential risks to surgical teams, topical therapy may be more appropriate. It is currently unclear which topical agent is most desirable in these contexts, but numerous studies have reported successful use of 5-fluorouracil (5-FU), ${ }^{8,11-13}$ mitomycin $C,{ }^{14,15}$ and interferon $2 \alpha^{16,17}$ as sole therapy or as an adjuvant to surgery. The low cost, easy storage, ${ }^{18}$ and wide availability of 5-FU in Sub-Saharan Africa make it a particularly advantageous treatment in this context.

5-FU has been shown to be both safe ${ }^{11}$ and effective $\mathrm{e}^{8,11-13,19,20}$ in the treatment of OSSNs in previous reports, eg, by Midena et $\mathrm{al}^{8}$ who published a case series demonstrating complete regression of neoplastic cells to normal conjunctival epithelium within 3 months of initiating treatment with 5-FU. However, there is a paucity in the literature on the impact that HIV infection may have on the efficacy of 5-FU in patients with OSSN. Given the high association rates with $\mathrm{HIV}^{4,21-24}$ and tendency for HIV patients to have more aggressive tumors, ${ }^{4,24}$ it is important to gain an understanding of whether OSSNs respond differentially to 5-FU according to their host's HIV status.

This retrospective hospital-based case series was designed to estimate the prevalence of HIV infection among the OSSN population in Angola and comment on the presenting features of OSSNs in HIV-positive and HIV-negative patients. It was also our intention to contribute data on the efficacy of 5-FU for treating OSSN and to provide a novel insight into whether HIV status modifies the success of 5-FU therapy for patients with tumors of the ocular surface.

\section{Materials and methods}

Photographic data were obtained for all patients presenting to the Boa Vista Eye Clinic (Benguela, Angola) with OSSNs between October 2011 and July 2013. Photographs of patients' eyes along with basic demographic information (age and sex) were taken for monitoring purposes at presentation and at each subsequent visit (mean interval 28 days). A total of 82 patients presented with OSSN in this period. All patients received an HIV test at presentation, and the photographs were stored according to serotype and by a numbered code in order to preserve confidentiality. Due to lack of laboratory access, it was not possible to determine patients' CD4 counts.

Each patient was initiated on a course of 5-FU on first presentation. One course constituted $1 \% 5$-FU solution, one drop four times a day for 7 days (cost \$1 USD per treatment cycle). Follow-up consultations were scheduled 1 month later. Twenty-four patients returned for follow-up, and 58 failed to attend, representing a $29.3 \%$ follow-up rate. Patients who attended for follow-up had a repeat photograph and, in unresolved cases, were prescribed a repeat course of treatment following a 1-month recovery period. All patients who attended at least one follow-up consultation after a course of treatment were included for analysis in the treatment arm of the study. None of the included patients had a history of ocular surgery.

All photographs of included patients were examined to determine the presenting features of each tumor (leukoplakia, vascular abnormalities, irregular borders, pigmentation, and whether the lesion was raised), presence of pterigium, and laterality and extent of the lesion, including the number of quadrants affected and whether the conjunctiva, cornea, or both were involved. In cases where patients attended follow-up, the total number of treatment courses was recorded and repeat photographs were compared with initial images in order to assess OSSN changes in response to 5-FU. Treatment response was categorized into the following: complete resolution, partial resolution, or no response. Partial resolution denoted a tumor that displayed an obvious reduction in size but was not yet completely resolved. Findings were grouped according to HIV status.

Informed consent was obtained from patients for photographs, which were kept anonymous and confidential. Institutional health ethics committee approval was obtained for the collection of data and the study adhered to the tenets of the Declaration of Helsinki.

\section{Statistical analysis}

Proportions (expressed as percentages) and odds ratios were calculated in order to make relative comparisons of the frequency of presenting features between the HIV-positive and HIV-negative groups. Percentages were also calculated and displayed in charts for comparison of response after one treatment round, and to compare the number of treatment courses required to achieve complete resolution between the two groups.

\section{Results}

\section{Presenting OSSN features and proportion of patients with coexisting HIV infection}

A total of 82 patients presented with OSSN between October 2011 and July 2013. Of these patients, 21 (25\%) were HIVpositive. Proportions of presenting features of tumors in both groups are shown in Figure 1. The pretreatment photograph 
A

\begin{tabular}{|l|l|l|l|}
\hline \multirow{2}{*}{ Presenting feature/demographics } & \multicolumn{2}{|l|}{ Number of patients (proportion) } & \multirow{2}{*}{ Odds ratio } \\
\cline { 2 - 3 } & HIV-positive & HIV-negative & \\
\hline Age range (years) and mean & $22-55$ mean: 38 & $21-68$ mean: 34 & N/A \\
\hline Sex: female & $14(67)$ & $30(50)$ & 2.0 \\
\hline Sex: male & $7(33)$ & $30(50)$ & 0.5 \\
\hline Raised lesion & $21(100)$ & $56(93)$ & 1.5 \\
\hline Leukoplakia & $20(95)$ & $45(75)$ & 6.0 \\
\hline Pigmentation & $17(81)$ & $37(62)$ & 2.6 \\
\hline Irregular borders & $20(95)$ & $49(82)$ & 2.1 \\
\hline Vascular abnormality & $20(95)$ & $50(83)$ & 4.0 \\
\hline Presence of all five (above) features & $14(67)$ & $15(25)$ & 6.0 \\
\hline Concurrent pterigium & $7(32)$ & $20(33)$ & 1.0 \\
\hline Laterality: nasal aspect & $16(76)$ & $48(80)$ & 0.8 \\
\hline Laterality: temporal aspect & $3(14)$ & $8(13)$ & 1.1 \\
\hline Laterality: both & $2(10)$ & $4(7)$ & 1.6 \\
\hline Conjunctival and corneal involvement & $13(62)$ & $35(58)$ & 1.2 \\
\hline One quadrant involved & $8(38)$ & $27(45)$ & 0.8 \\
\hline Two quadrants involved & $11(52)$ & $24(40)$ & 1.7 \\
\hline Three or four quadrants involved & $2(10)$ & $9(15)$ & 0.6 \\
\hline
\end{tabular}

B

\section{Percentage of male/females with OSSN in HIV+/- groups}

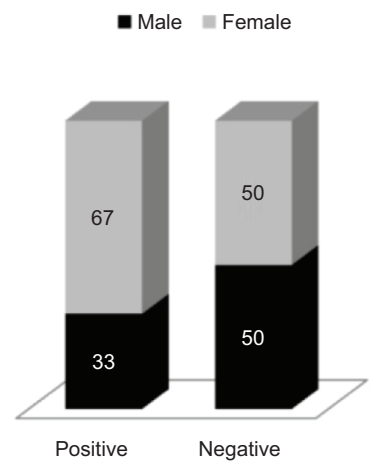

C

\section{Comparison of proportions of presenting OSSN features in $\mathrm{HIV+/-groups}$}

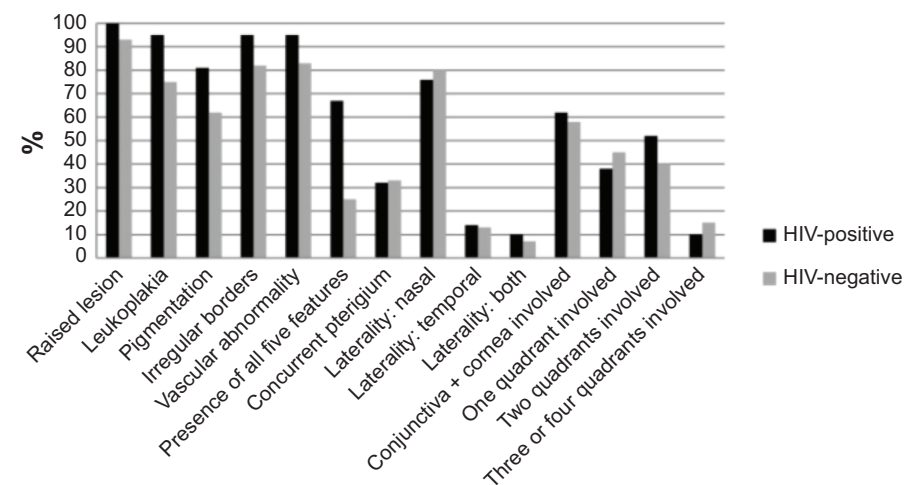

Figure I (A) Summary of patient demographics and absolute numbers/proportions of presenting OSSN features with odds ratios. (B) Proportion of male/females presenting with OSSN in HIV-positive and HIV-negative groups. (C) Comparison of proportions of each presenting OSSN feature between HIV-positive and HIV-negative groups. Abbreviations: HIV, human immunodeficiency virus; N/A, not applicable; OSSN, ocular surface squamous neoplasia.

for patient 47 was missing, so could not be included in the analysis of presenting features.

\section{Response of OSSN to 5-FU}

Patients who attended at least one follow-up appointment after 5-FU therapy were included in the analysis of treatment efficacy. The number of treatment courses varied between one and four (mean 1.5). Eight (38\%) HIV-positive and 16 (20\%) HIV-negative patients met the inclusion criteria. Ninety-one percent of OSSNs across both groups showed a degree of response to 5-FU after the first course. Figure 2 demonstrates examples of tumor regression in response to therapy in HIVpositive patients. In the HIV-positive group, five $(62.5 \%)$ displayed complete clinical resolution, two (25\%) showed partial resolution, and one $(12.5 \%)$ failed to respond by the last follow-up consultation attended. Of the five patients who displayed complete resolution, three had received one treatment course, one had received three courses, and one had received four courses. Of the two patients who experienced partial resolution, one had received two courses and the other had received one course. The patient who showed no response had received one course.

In the HIV-negative group, five (31\%) displayed complete resolution, ten (63\%) showed partial resolution, and one (6\%) patient did not respond by the last follow-up. Of the completely resolved cases, three patients had received two treatment courses and two patients had received one course. Of those who showed partial resolution, eight had received one course and one had received two courses. The patient who failed to respond had received four courses.

Regarding the patients who completely responded to treatment, $60 \%$ of HIV-positive patients and $40 \%$ of HIVnegative patients achieved complete resolution after one course. After the second course, all of the seronegative 

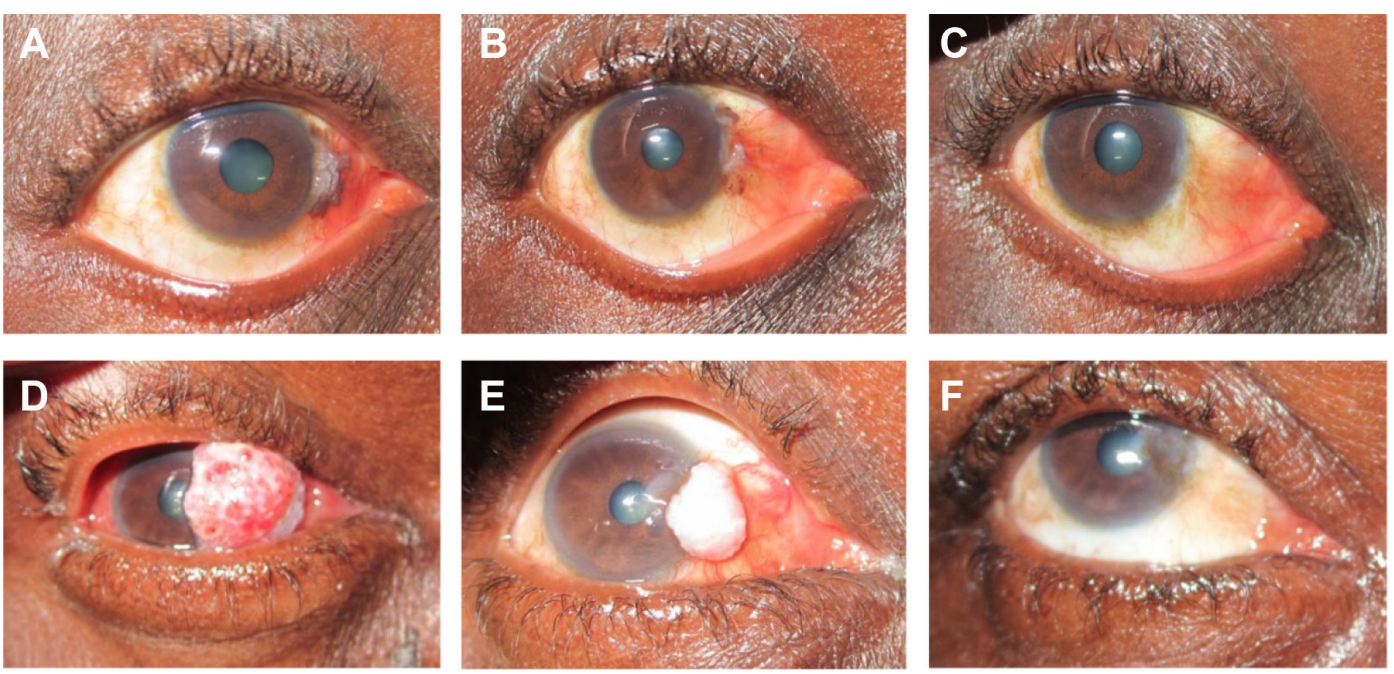

Figure 2 Clinical regression of OSSN in HIV-positive patients. (A-C) Photographs of patient I at presentation, and after three and four cycles of 5-FU, respectively. (D-F) Photographs of patient 13 at presentation, and after two cycles and three cycles of 5-FU, respectively.

Abbreviations: HIV, human immunodeficiency virus; OSSN, ocular surface squamous neoplasia.

patients had responded, while the complete response rate in the HIV group was still $60 \%$. Complete resolution in the HIV group was seen in $80 \%$ and $100 \%$ of cases after the third and fourth courses of treatment, respectively (Figure 3A).

After the first course of 5-FU, OSSNs had displayed some degree of clinical regression in $87 \%$ of the HIV-positive patients and $94 \%$ of the HIV-negative patients. Resolution was complete at this stage in $36 \%$ of HIV-positive cases and $13 \%$ of HIV-negative cases (Figure 3B).

\section{Complications}

No patients experienced serious side effects of 5-FU. One patient (patient 30) developed a small patch of dermatitis on the lower eyelid which resolved spontaneously after 1 week. This event occurred early on in the study period and patients were subsequently advised to clean around the eye thoroughly after administration of 5-FU. There were no reported complications subsequent to this episode.

\section{Discussion}

The aim of this retrospective hospital-based case series was to estimate the rate of HIV infection in OSSN patients in Angola, study the presenting features of these tumors, and to monitor the response to 5-FU treatment in HIV-positive and HIV-negative individuals.

\section{HIV infection rates in OSSN patients}

One quarter of the patients who presented with OSSN were HIV-positive. This proportion is 9-13 times higher than that in the general population, which the government states to be between $1.9 \%$ and $2.8 \% .{ }^{25}$ This suggests that a high index of clinical suspicion of HIV is important for OSSN patients and an HIV test should be considered, although

\section{A Cumulative percentages of completely resolved cases after treatment courses in HIV+l- groups}

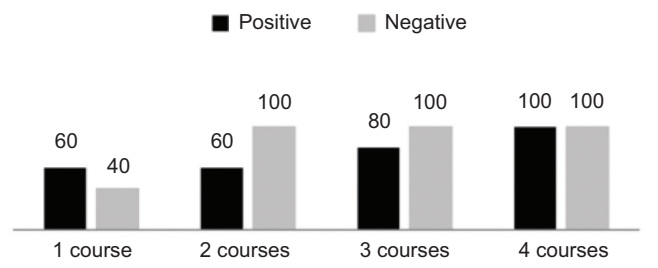

B
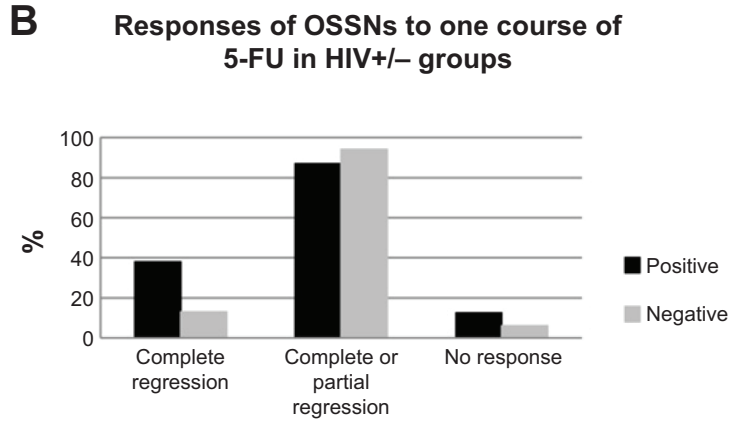

Figure 3 (A) Cumulative percentage of completely resolved cases after treatment courses in cases which reached complete regression. (B) Responses of OSSNs in HIVpositive and HIV-negative patients after one course of 5-FU treatment.

Abbreviations: HIV, human immunodeficiency virus; OSSN, ocular surface squamous neoplasia; +, positive; -, negative; 5FU, 5-fluorouracil. 
the increased risk is markedly lower than association rates reported in other Sub-Saharan nations (71\% in Uganda and $86 \%$ in Malawi). ${ }^{7}$ This may be a reflection of a lower HIV prevalence rate in Angola as a result of the civil war during the HIV epidemic.

\section{Presenting features of OSSN in HIV- positive and HIV-negative patients}

On comparing OSSN features in the HIV-positive and HIVnegative groups, it emerged that each of the five features (raised, leukoplakic, pigmented, presence of vascular abnormalities, and irregular borders) was more common in HIVpositive individuals (Figure 1C). The proportion of patients who exhibited all of these features was markedly higher in the HIV-positive group than in the HIV-negative group $(67 \%$ versus $25 \%$, respectively). These statistics yield an odds ratio of 6, suggesting it can be estimated that an OSSN patient with all five features has an approximately $60 \%$ increased risk of concurrent HIV infection.

We also note that there was a larger proportion of females than males with OSSN in the HIV-positive group (Figure 1B), whereas in western countries OSSN typically affects elderly males. ${ }^{6,26}$ A shifting trend for OSSN to affect women more has been previously noted in the literature, ${ }^{6}$ along with the recognition that this apparent excess risk may just be a reflection of the fact that HIV is more prevalent in women in Sub-Saharan Africa. ${ }^{27}$ In either case, it is relevant to note that females presenting with OSSN in Angola may have a higher risk of HIV infection than males.

\section{Response to and complications of 5-FU}

The results in the treatment arm of this study are congruent with previous studies ${ }^{1,5,10,11,26,27}$ that have shown 5-FU to be a safe and effective treatment for OSSN. Ninety-one percent $(n=21)$ of the tumors displayed partial or complete regression after one course of 5-FU. Only two patients (one from each group) failed to show any response by their last visit. We observed fewer complications compared with two recent studies $^{26,27}$ that reported complications in more than half of their patients using a 2 -week regimen of $1 \% 5-\mathrm{FU}$, compared with one patient in this study who had a shorter course.

A comparison of the 5-FU treatment response between HIV-positive and HIV-negative patients has not previously been reported in the literature. In this study, we demonstrate promising and comparable treatment responses between the two groups, and suggest that 5-FU may be an appropriate primary treatment for OSSN patients irrespective of HIV status. We compared the treatment response between the groups after one round of 5-FU ( $P=0.896$ comparing complete/partial resolution after one treatment, HIV-negative versus HIV-positive), and the number of courses required to reach complete clinical resolution (Figure 3 ). Both comparisons indicate a similar response to 5-FU when comparing HIV-positive and HIV-negative individuals and it is unlikely that HIV infection plays any significant role in modifying the efficacy of 5-FU treatment for these tumors. Due to the varying number of treatment rounds that patients received and the poor rate of return for follow-up across both groups, it was not possible to compare response at the last follow-up attended.

\section{Limitations}

This study has numerous limitations due to location, lack of resources, and patient demographics. First, we were unable to make histological diagnoses or confirm eradication of neoplastic cells due to the lack of histopathology or cytology services. Access to these services would have given a higher degree of certainty as to the efficacy of 5-FU in the study population. Second, lack of availability of laboratory facilities meant that we could not ascertain CD4+ counts in HIV-positive patients. It would be useful to know CD4+ counts in order to look for trends between OSSN features or response to 5-FU and severity of HIV disease. Third, our analysis of 5-FU efficacy was limited due to poor patient follow-up rates. Follow-up is frequently a challenge at Boa Vista due to the long distances many patients need to travel for consultations, meaning that some patients will not return for follow-up if they are satisfied with their results after treatment. Fourth, the sample size was relatively small for a retrospective study design. Preferably we would have access to more data to increase our confidence that the findings were not due to chance. However, our results are noteworthy and hopefully will be confirmed by randomized controlled trials in the future.

\section{Conclusion}

In Angola, OSSN is associated with higher rates of HIV infection compared with rates in the general population; OSSN may indicate up to a 13 times increased HIV risk. This a striking association, although not as marked as associations reported in other Sub-Saharan nations, possibly due to relatively lower HIV rates in the general population of Angola. In settings of the developing world where HIV prevalence is high and access to histopathology is limited, primary treatment with 5-FU eye drops can be an effective strategy for management of OSSN without incurring the 
costs and risks of surgery. The vast majority of tumors show significant clinical regression after one course of 5-FU. For a tumor which frequently coexists with HIV, it is important that 5-FU is not impeded by infection. Our findings show that OSSN responds well to 5-FU therapy, irrespective of HIV status.

\section{Disclosure}

This research received no specific grant from any funding agency in the public, commercial, or not-for-profit sectors. The authors report no conflicts of interest in this work.

\section{References}

1. Lee GA, Hirst LW. Ocular surface squamous neoplasia. Surv Ophthalmol. 1995;39:429-450.

2. Gichuhi S, Irlam JJ. Interventions for squamous cell carcinoma of the conjunctiva in HIV-infected individuals. Cochrane Database Syst Rev. 2007;2:CD005643.

3. Poole TG. Conjunctival squamous cell carcinoma in Tanzania. Br J Ophthalmol. 1999;83:177-179.

4. Shields CL, Ramasubramanian A, Mellen PL, Shields JA. Conjunctival squamous cell carcinoma arising in immunosuppressed patients (organ transplant, human immunodeficiency virus infection). Ophthalmology. 2011;18:2133-2137.

5. Nagaiah G, Stotler C, Orem J, Mwanda WO, Remick SC. Ocular surface squamous neoplasia in patients with HIV infection in sub-Saharan Africa. Curr Opin Oncol. 2010;22:437-442.

6. Karcioglu ZA, Wagoner MD. Demographics, etiology, and behavior of conjunctival squamous cell carcinoma in the 21 st century. Ophthalmology. 2009;116:2045-2046.

7. Waddell KM, Lewallen S, Lucas SB, Atenyi-Agaba C, Herrington CS, Liomba G. Carcinoma of the conjunctiva and HIV infection in Uganda and Malawi. Br J Ophthalmol. 1996;80:503-508.

8. Midena E, Degli C, Valenti M, de Belvis V, Boccato P. Treatment of conjunctival squamous cell carcinoma with topical 5-fluorouracil. Br J Ophthalmol. 2000;84:268-272.

9. Waring GO 3rd, Roth AM, Ekins MB. Clinical and pathological description of 17 cases of corneal intraepithelial neoplasia. Am J Ophthalmol. 1984;97:547-559.

10. Fraunfelder FT, Wingfield D. Management of intraepithelial conjunctival tumors and squamous cell carcinomas. Am J Ophthalmol. 1983;95:359-363.

11. Parrozzanini R, Lazzarini D, Alemany-Rubio E, Urban F, Midena E. Topical 1\% 5-fluorouracil in ocular surface squamous neoplasia: a long-term safety study. Br J Ophthalmol. 2011;95:355-359.
12. Yamamoto N, Ohmura T, Suzuki H, Shirasawa H. Successful treatment with 5-fluorouracil of conjunctival intraepithelial neoplasia refractive to mitomycin-C. Ophthalmology. 2002;109:249-252.

13. Yeatts RP, Ford JG, Stanton CA, Reed JW. Topical 5-fluorouracil in treating epithelial neoplasia of the conjunctiva and cornea. Ophthalmology. 2000;102:1338-1344.

14. Russell HC, Chadha V, Lockington D, Kemp EG. Topical mitomycin C chemotherapy in the management of ocular surface neoplasia: a 10-year review of treatment outcomes and complications. Br J Ophthalmol. 2010;94:1316-1321.

15. Frucht-Pery J, Rozenman Y. Mitomycin C therapy for corneal intraepithelial neoplasia. Am J Ophthalmol. 1994;117:164-168.

16. Sturges A, Butt AL, Lai JE, Chodosh J. Topical interferon or surgical excision for the management of primary ocular surface squamous neoplasia. Ophthalmology. 2008;115:1297-1302.

17. Shah SU, Kaliki S, Kim HJ, Lally SE, Shields JA, Shields CL. Topical interferon alfa-2b for management of ocular surface squamous neoplasia in 23 cases: outcomes based on American Joint Committee on Cancer Classification. Arch Ophthalmol. 2012;130:159-164.

18. Nanji AA, Sayyad FE, Karp CL. Topical chemotherapy for ocular surface squamous neoplasia. Curr Opin Ophthalmol. 2013;24:336-342.

19. Rudkin A, Muecke J. Adjuvant 5-fluorouracil in the treatment of localised ocular surface squamous neoplasia. Br J Ophthalmol. 2011;95:947-950.

20. Bahrami B, Greenwell T, Muecke JS. Long-term outcomes after adjunctive topical 5-flurouracil or mitomycin $\mathrm{C}$ for the treatment of surgically excised, localized ocular surface squamous neoplasia. Clin Exp Ophthalmol. 2014;42:317-322.

21. Karp CL, Scott IU, Chang TS, Pflugfelder SC. Conjunctival intraepithelial neoplasia: a possible marker for human immunodeficiency virus infection? Arch Ophthalmol. 1996;114:257-261.

22. Ateenyi-Agaba C. Conjunctival squamous-cell carcinoma associated with HIV infection in Kampala, Uganda. Lancet. 1995;345:695-696.

23. Weinstein JE, Karp CL. Ocular surface neoplasias and human immunodeficiency virus infection. Curr Opin Infect Dis. 2013;26:58-65.

24. Makupa II, Swai B, Makupa WU, White VA, Lewallen S. Clinical factors associated with malignancy and HIV status in patients with ocular surface squamous neoplasia at Kilimanjaro Christian Medical Centre, Tanzania. Br J Ophthalmol. 2012;96:482-484.

25. HIV and AIDS estimates (2013) [webpage on the Internet]. Switzerland: UNAIDS; 2014. Available from: http://www.unaids.org/en/ regionscountries/countries/angola/. Accessed October 14, 2014.

26. Alves LF, Fernandes BF, Burnier JV, Zoroquiain P, Eskenazi DT, Burnier MN Jr. Incidence of epithelial lesions of the conjunctiva in a review of 12,102 specimens in Canada (Quebec). Arq Bras Oftalmol. 2011;74:21-23.

27. Furahini G, Lewallen S. Conjunctival squamous cell carcinoma (letter). Ophthalmology. 2010;117:1458.
Clinical Ophthalmology

\section{Publish your work in this journal}

Clinical Ophthalmology is an international, peer-reviewed journal covering all subspecialties within ophthalmology. Key topics include: Optometry; Visual science; Pharmacology and drug therapy in eye diseases; Basic Sciences; Primary and Secondary eye care; Patient Safety and Quality of Care Improvements. This journal is indexed on Submit your manuscript here: http://www.dovepress.com/clinical-ophthalmology-journal

\section{Dovepress}

PubMed Central and CAS, and is the official journal of The Society of Clinical Ophthalmology (SCO). The manuscript management system is completely online and includes a very quick and fair peer-review system, which is all easy to use. Visit http://www.dovepress.com/ testimonials.php to read real quotes from published authors. 